\title{
An In-Service Primary Teacher's Responses to Unexpected Moments in the Mathematics Classroom
}

\author{
Sumeyra Dogan Coskun ${ }^{1}$ (D) Mine Isiksal Bostan ${ }^{2} \cdot$ Tim Rowland $^{3}$
}

Received: 27 February 2019 / Accepted: 4 January 2020/Published online: 27 January 2020

(C) Ministry of Science and Technology, Taiwan 2020

\begin{abstract}
The purpose of this case study is to investigate the triggers of unexpected (contingent) moments during one in-service primary teacher's teaching of the measurement of length and perimeter, to identify this teacher's responses to these moments, and to examine how these responses change the flow of the measurement of length and perimeter instruction. Ten lessons were recorded: the triggers of the contingent moments during these lessons were analyzed according to Rowland, Thwaites and Jared's (2015) framework and the teacher's responses were analyzed according to Stockero and Van Zoest's (Journal of Mathematics Teacher Education, 16(2), 125-147, 2013) response types. The findings of this study showed that the contingent moments in these lessons resulted from the students' incorrect answers, questions, and ideas, and the availability of materials. Moreover, the analysis of the teacher's responses indicated that there were differences in the teacher's spontaneous responses during the lessons, both in terms of the different types and the depth of the given responses. In addition, the teacher's way of responding affected the flow of the measurement of length and perimeter instruction.
\end{abstract}

Keywords Contingent moments $\cdot$ Teacher response $\cdot$ Response types $\cdot$ Measurement of length and perimeter

Electronic supplementary material The online version of this article (https://doi.org/10.1007/s10763-02010050-4) contains supplementary material, which is available to authorized users.

Sumeyra Dogan Coskun

s-dogan@ogu.edu.tr

Mine Isiksal Bostan

misiksal@metu.edu.tr

Tim Rowland

Tim.Rowland@uea.ac.uk

Extended author information available on the last page of the article 


\section{Introduction}

The following interchange occurred in a lesson on perimeter with a fourth grade class. When the students were discussing how to calculate the perimeter of a hexagon, the response of one student surprised the teacher:

Student $_{3}$ :

Student $_{4}$ :

We ask: How does the teacher respond to students? How does the teacher's response affect the flow of the measurement of perimeter instruction?

When the complex, rich, and dynamic nature of classrooms is considered, there may be many unpredictable and unexpected moments during instruction. Brookfield (2006) states that teaching is "full of unexpected events, un-lookedfor surprises, and unanticipated twists and turns" (pp. xi-xii) and he asserts that no matter how teachers plan their instruction, they can be confident that there will be uncertain moments. Rowland et al. (2015) found that these moments usually result from students' ideas, suggestions, questions, (un)availability of materials, and teacher insight. A teacher's ability to notice these unexpected moments and to respond contingently is recognized as an important element of effective instruction (Anthony, Hunter \& Hunter, 2015). Similarly, the National Council of Teachers of Mathematics (2000) emphasizes that teachers' abilities to notice students' ideas and questions, and to make quick pedagogical decisions on activities or strategies to be implemented are important parts of effective teaching. If teachers interpret their interaction with a student or student group in a helpful way, they can address and overcome their students' misunderstandings, which is one of the indicators of teaching quality (Ball, 1997). The important point here is to consider the ideas raised by students and to determine which ones are important considering the lesson objectives (Sawyer, 2004). That is to say, although making quick decisions about how to respond to these contingent moments is important, responding in a way that helps students learn the content meaningfully is critical.

Accepting that these contingent moments are important parts of mathematics instruction, teachers need to be prepared for some discrepancies between their lesson plan and the enactment of it in their classrooms. Therefore, it would be beneficial to study contingent moments and teachers' responses to contingent moments. Teachers plan how a lesson would flow from the beginning to the end of instruction. However, there may be changes in the flow because of contingent moments. While some of these moments can contribute to flow of instruction as they are related to objectives, some of them can be disruptive to the lesson. Therefore, examining contingent moments and teachers' responses to them ought to include the ways that such responses affect how the lesson proceeds. That is, our assumption is that a teacher's response type to a contingent moment changes the flow of instruction. In this context, the purpose of this case study is to examine the triggers of contingent moments occurring when one inservice primary teacher is teaching the measurement of length and perimeter, to identify this teacher's responses to these moments, and to examine how these responses change the flow of the instruction of the related topics. 


\section{What Is Contingency?}

The NCTM (2000) emphasizes that mathematics classrooms should be places in which students engage in meaningful dialogues. Throughout these dialogues, it is to be expected that there will be many different student ideas, suggestions, or questions, and some of them will be unexpected for the teachers. Teachers can often predict their students' most likely questions and suggestions (Schoenfeld, 1998). Teachers hope and expect that their students will perform the planned or intended actions during an activity. However, students may ask questions or make suggestions that are not planned for or anticipated. These unexpected moments which are triggered by students' contributions are given different names by different researchers such as "potentially powerful learning opportunity" (Davis, 1997, p. 360), "critical moments" (Walshaw \& Anthony, 2008, p. 527), and "pivotal teaching moments" (Stockero \& Van Zoest, 2013, p. 127). In addition to the above names, Rowland and his colleagues (2015) have also provided evidence of other triggers of unexpected moments throughout mathematics instruction. Specifically, Rowland and his colleagues (2015) found that unexpected moments can also be triggered by teacher insight, or by (un)availability of teaching materials. They use the term "contingency" to refer to these moments. One of these triggers, "teacher insight," concerns moments in which teachers realize that they are not being helpful — for instance, if they give an example that is not ideal for the topic - and try to correct themselves. Other than realizing the moments that are not helpful or ideal, taking a student's idea into consideration and discussing the idea may also result in a moment of teacher insight, as the teacher realizes the importance of the student's idea (Rowland et al., 2015).

The final trigger of contingent moments is the unexpected availability or unavailability of teaching materials needed to achieve the objectives of the lesson (Rowland et al., 2015). Kilundo (2002) asserts that it is nearly impossible for teachers to help their students to learn content meaningfully without using such materials. In accordance with this assertion, teachers plan how they would use materials to help students better understand the content. If teachers cannot think of an alternative material when they are not available or become unavailable, then the unavailability of the material would be a trigger of a contingent moment. Despite Kilundo's (2002) explanation, some teachers may not plan to use materials to present the content as they think students would comprehend the content easily. However, when teachers notice that their students have some difficulties in understanding the content, they might incorporate materials readily available to them, or create their own materials. That is, if teachers cannot find suitable ones, they need to improvise and make the best of the materials available to them. Then, the availability of the material would be a trigger of a contingent moment.

In order to emphasize the importance of contingency, Rowland and Zazkis (2013) state that teaching is not "attending to prescribed scenarios and delivering a predetermined curriculum"; otherwise, it would be enough to know the curriculum. In the same way, Towers and Davis (2002) state that lesson plans "should not be framed in terms of trajectories, itineraries, or blueprints, but as exercises in anticipation. The lesson plan is an event of preparation, not prespecification" (p. 337). That is, although teachers can plan some of these moments, they cannot be sure about how the lesson and the lesson activities will proceed. Knowing what to do in the moment is vital: Lampert (2001) states that teachers need to respond to their students' questions or ideas immediately during instruction. 


\section{Teacher Responses}

Rowland et al. (2015) also found that teachers' responses to unexpected ideas and suggestions from students can be of three types: to ignore, to acknowledge and put aside, and to acknowledge and incorporate. Stockero and Van Zoest (2013) also state that teachers can respond by ignoring or acknowledging but continuing their plan. Furthermore, they point out that teachers can respond to these moments by emphasizing mathematical meaning, pursuing student thinking, and extending or making connections. The first of these response types, to ignore or dismiss, is related to moments in which teachers simply set aside the student's idea by saying something like "We are not talking about that now" as s/he focuses on what had been planned (Stockero \& Van Zoest, 2013, p. 137). Acknowledging but continuing the plan occurs when teachers accept the student's idea or question but do not deviate from their plan. For example, when a teacher shows how to add two 2-digit numbers like $25+26$ in columns, a student might suggest to double 25 and then add 1 to find the answer. If the teacher acknowledges that the student's strategy is correct but continues with his/her plan, then the teacher's response type is categorized as acknowledging but continuing. On the other hand, the teacher could recognize the student's approach as an opportunity to engage other students in considering alternative strategies. Another possible response would be to pursue student thinking by exploring the student's idea in order to find out more about what $\mathrm{s}$ /he was thinking. The response, extending or making connections, "occurs when teachers go beyond the topic that students are working on in the lesson to revisit and make connections to past learning or to foreshadow or lay a foundation for future learning" (Stockero \& Van Zoest, 2013, p. 138). As can be understood from the many response types, the way teachers respond to unexpected moments might have an impact on the flow of the instruction. Therefore, in the present study, after identifying the contingent moments in one in-service primary teacher's teaching of the measurement of length and perimeter, and the teacher's response types to these moments, we aim to examine how these contingent responses affect the flow of the instruction.

\section{Measurement of Length and Perimeter}

The measurement of length and perimeter are important topics, and students encounter them in different grade levels in various countries (Ministry of National Education, 2015; NCTM, 2000). Although students engage in length measurement activities from the first grade onward, studies show that students struggle with the measurement of length and perimeter. In the case of length measurement, researchers find that often students do not understand which attribute of an object is being measured, and thus they do not know what is being counted on a ruler. However, the most important aspect of measurement is "knowing what the attribute to be measured is" (Baturo \& Nason, 1996, p. 238). Specifically, students who do not understand the meaning of length measurement tend to count hash marks on the ruler instead of counting the line segments between two consecutive hash marks (Bragg \& Outhred, 2004). Since students cannot conceptually understand the measurement of length, they have difficulties in the measurement of perimeter as well. They cannot comprehend that perimeter is also one-dimensional measure. Furthermore, they try to solve perimeter problems without understanding the reasoning behind the formula (Sherman \& Randolph, 
2004). Therefore, Smith, Sterling and Moyer-Packenham (2006) assert that measurement of length is "more than just learning how to use a ruler" (p. 30).

When the reasons for students' difficulties are examined, Stephan and Clements (2003) emphasize that teachers tend to focus on the procedures needed to solve the problems rather than the reasons or the concepts behind them, and they conclude that "Something is clearly wrong with measurement instruction" (p. 3). Teachers could possibly be faced with unexpected questions throughout their instruction, and some of these questions could provide clues about students' misconceptions for the topics of measurement of length and perimeter. If teachers notice these clues and know how to address these misconceptions, they can turn these unexpected questions into opportunities to support students' understanding (Jaworski, 2004).

\section{Purpose of the Study}

There are several studies that examine contingent moments in mathematics classes in countries such as South Africa, England, Norway, and the USA (e.g. Abdulhamid, 2017; Kleve \& Solem, 2015; Rowland et al., 2015; Stockero \& Van Zoest, 2013). These studies include how pre-service teachers' abilities to act contingently develop over time, and how teachers respond to contingent moments initiated by a student. If teachers are able to benefit from students' unexpected contributions, they can be turned into desirable moments (Foster, 2015). Although the triggers of contingent moments may not be specific to topics, teachers' responses may be topic-specific (Cross, 2009; Jacobs \& Empson, 2016). Previous studies examined the triggers of contingent moments related to the topics of odd/even numbers, operations with numbers, fractions, and area measurement, and teachers' responses to these moments (Kleve \& Solem, 2015; Rowland et al., 2015). The current study examines contingent moments throughout the measurement of length and perimeter instruction and a teacher's responses to these moments. By considering different topics, it may be possible to explore a consistency or pattern among teachers' responses for different topics.

A growing number of researchers have agreed that there is ample evidence of the benefits and importance of contingent moments, for both students and teachers, if teachers know how to respond to them (Forzani, 2014; Stockero \& Van Zoest, 2013). Specifically, there are studies showing how teachers can use students' unexpected ideas as potentially powerful learning opportunities to extend their students' learning (Davis, 1997; Jacobs, Lamb \& Philipp, 2010). However, the availability of materials as a prompt for contingent moments is not given so much attention in the literature, even though it may positively affect how the lesson proceeds. The present study considered a contingent moment resulting from the availability of materials in addition to the moments that resulted from the students' ideas and questions. Hence, the findings of this study may provide practical implications for teachers to notice how they can use the materials available in their classrooms. Based on the literature review above, our aims in this study were to identify the triggers of contingent moments in one in-service primary teacher's measurement of length and perimeter instruction, to understand how the teacher responded to these moments in her interaction with her students, and also to examine the effects of the teacher's responses on the flow of measurement of length and perimeter instruction. Specifically, the purpose of this study was to answer the following research questions: 
What are the triggers of contingent moments occurring during a lesson on the measurement of length and perimeter taught by an in-service primary teacher?

How does the teacher respond to these contingent moments?

How do the teacher's responses to these contingent moments change the flow of the measurement of length and perimeter instruction?

\section{Methodology}

In this paper, we analyze and report a case study, which is "the study of the particularity and complexity of a single case, coming to understand its activity within important circumstances" (Stake, 1995, p. xi). It is examined to understand the complexity of the case and the interactions within its real-life context (Yin, 2002). The relationship between the case and the context of the study is relevant to the findings, and we now describe the structural context of the study.

\section{Context and Participant}

The study took place in Turkey, where the primary school mathematics curriculum has four content strands: numbers, geometry, measurement, and data. Elementary students have five hours of mathematics lessons per week (MoNE, 2015). Length measurement, one of the topics of this study, is introduced in the first grade by comparing the length of two or three objects. First, they measure the lengths of these objects using nonstandard units, such as paper-clips or beans. Then, in the second grade, they come to realize the need to use standard length measurement units. They learn to use a tape measure and record their measurement results in centimeters or meters. Students encounter the perimeter concept in the third grade and learn how the perimeter of a geometric figure is measured. In the fourth grade, students learn the kilometer and millimeter as standard length measurement units, explain the relationships between different length measurement units, and solve/pose problems related to length measurement. In addition, students learn to calculate the perimeter of plane figures, the relationship between the perimeter of a square and a rectangle and their sides, and solve and pose problems related to perimeter (MoNE, 2015).

The participant of this case study is a primary school teacher, assigned the pseudonym "Kubra," who was a highly-regarded fourth grade teacher willing to participate in the study. The willingness to participate is important in case studies, so that the participant will share his/her ideas, beliefs, or concerns directly related to the focus of the study. Kubra had graduated from one of the 4-year teacher education programs in the Department of Primary Teacher Education in Turkey and had 15 years' teaching experience. While the data were collected, she was teaching a fourth grade class with 30 students. Kubra stated that she had worked tirelessly throughout her teaching career to change her students' beliefs about mathematics by using materials and by creating an environment in which students express themselves.

\section{Data Collection and Analysis}

In order to address the research questions of this study, video recordings of classroom observations, semi-structured interviews with Kubra, and field notes were used. 
Although the curriculum assigns 12 lesson hours in total to the measurement of length and perimeter, Kubra finished the assigned topics in ten lesson hours (see supplementary file 1 for the Overview of Kubra's Measurement of Length and Perimeter Lessons). The camera was placed at the back of the classroom in order not to disrupt the learning environment. The video recordings and transcriptions of them served as the main data for the identification of contingent moments in these lessons. To support the data obtained from the observations and the video recordings and to make the points to be examined later easier to remember (Silverman, 1993), field notes were also used. The observerresearcher took field notes and sat close to the video camera. Furthermore, the observerresearcher also recorded possible questions that could be asked during the interviews.

The third data source, interviews with Kubra, provided additional information about her feelings, beliefs, and thoughts (Patton, 2002). Before conducting these interviews, the first author met with Kubra just after each lesson to get a sense of what went well or what did not go so well for her. The focus of these informal interviews was to collect information about whether or not Kubra was aware of any missed opportunities. Following Kubra's daily instruction, the video recordings were viewed by the observer/researcher and the dialogues between Kubra and her students during the contingent moments were transcribed in order to prepare semi-structured questions for the later interviews with Kubra. The transcriptions were shared with Kubra and she was invited to confirm what was written. Most of the interview questions were designed to recall some contingent moments in her lessons and to investigate Kubra's reasons for her responses to them. For this purpose, questions specific to particular contingent moments were asked such as, "Why did you respond to this moment in that way?" or "What could you have done instead of what you did?" During the interviews, video-stimulated recall was employed to examine Kubra's thoughts, as videostimulated recall is used "to prompt learners' recollections of their thoughts at the time they originally performed a task or participated in an event" (Mackey, 2012, p. 27). That is, Kubra was given stimuli and asked to comment on her responses to the contingent moments in the lessons. For this purpose, selected contingent moments were watched together on video, to help Kubra remember these moments and provide guidance for what to reflect on before the related questions were asked. Although video-stimulated recall helps participants more accurately comment on particular moments, being exposed to the same moments twice may allow the participants to reconsider their thoughts (Gass \& Mackey, 2000). That is, watching the video might have allowed Kubra to reconsider her responses at the time of interviews and report what she believed was right. To prevent this limitation, the video-stimulated interviews were conducted relatively soon after each lesson since researchers mention that the shorter length of time between the recorded moment and the video-stimulated recall interview helps participants remember these moments more accurately (Ericsson \& Simon, 1999). These interviews were also video recorded for later analysis.

Data analysis began with the identification of contingent moments during the instruction by means of the field notes containing short explanations about the contingent moments and the dialogues exchanged between Kubra and her students throughout the contingent moments. Then, to enable the researchers be familiar with Kubra's teaching of measurement of length and perimeter, the researchers watched the video recordings of the lessons. After the researchers had individually identified the contingent moments in each lesson, they compared the moments that they identified with 
each other. Throughout this process, the researchers noted whether there were contingent moments in addition to the moments provided in the field notes. Determining what is or is not a contingent moment is problematic. Therefore, in this study, the moments that appeared to be unexpected for Kubra and resulted from students' contributions, teacher insight, or (un)availability of materials were taken to be contingent moments. After the researchers agreed that there were ten contingent moments, they made ten extracts from the video recordings. This enabled the researchers to re-watch and discuss the trigger of each contingent moment. Following Rowland et al. (2015), while rewatching the video segments, the "trigger" of each contingent moment was categorized using the three above-explained codes: student's answer/question/idea, teacher insight, or (un)availability of materials. In addition to the trigger of each contingent moment, the researchers also examined the video segments and transcriptions of these segments to determine the response type of Kubra by underlining the key words and phrases that Kubra used. Then, watching the video recordings of the semi-structured interviews with Kubra helped us better understand her responses to these contingent moments with reference to the framework of Stockero and Van Zoest (2013). Finally, how Kubra's responses to these contingent moments changed the flow of the measurement of length and perimeter instruction was considered.

\section{Findings and Discussion}

Although five contingent moments arose in each of the two topics (measurement of length and perimeter), three of them were "yes/no" questions asked by the students to get approval. These questions were like "We should write, or include units next to numbers while solving problems, shouldn't we?" or "We should not make abbreviations in the units like centi and milli, should we?" and Kubra responded to these questions by just saying one word such as "yes" or "no." As can be understood from the above questions, these questions were different from the other contingent moments in which students asked questions or offered ideas so that Kubra could take the opportunity to involve other students in mathematical discussions. That is, since these questions were not really questions about mathematics, more about written presentation, Kubra's responses did not lead to missed opportunities. While the triggers of these yes/no moments were students' questions, Kubra's responses to them were to ignore/dismiss or to acknowledge but to continue. When the reasons for Kubra's responses were asked during the interviews, she simply stated that there was not a specific reason. Although seven of these moments which Kubra responded in depth were presented in the findings and discussion part of the study, these three other moments are also included in the following table to show a complete picture of triggers of contingent moments and Kubra's responses to these moments in the ten lessons (Table 1).

The findings of the study are presented with reference to (a) the trigger of the contingent moment and (b) the teacher's responses, including dialogues between students or between the teacher and the student(s) in chronological order. We include our interpretations of the thinking that led to Kubra's contributions to these dialogues. Furthermore, the findings and their discussion are combined to help readers to better understand contingent moments and responses to these contingent moments. Therefore, 
Table 1 An overview of the triggers of and Kubra's responses to contingent moments

\begin{tabular}{ll}
\hline Trigger & Response \\
\hline A student's idea & Ignore or dismiss \\
A student's question & Acknowledge but continue \\
A student's wrong answer & Acknowledge but continue \\
A student's question & Ignore or dismiss \\
Availability of materials & Extend or make connections \\
A student's idea & Pursue student thinking \\
A student's question & Extend or make connections \\
A student's question & Acknowledge but continue \\
A student's question & Acknowledge but continue \\
A student's question & Ignore or dismiss \\
\hline
\end{tabular}

we present our findings so that each of the triggers and responses of the teacher is exemplified and discussed considering the related literature.

\section{Contingent Moment 1: A Student's Idea-Ignore or Dismiss}

The first contingent moment, instigated by one of Kubra's students, was related to centimeter-to-meter conversion. After Kubra had explained that a meter is equal to 100 centimeters, one of Kubra's students pointed out the relationship between length measurement and decimals (see supplementary file 2 for the dialogue). The student may have made the connection between these topics because they were taught decimals prior to learning about length measurement. However, rather than questioning the student's idea as an opportunity to make a connection between different mathematical perspectives, Kubra told the student that they were not talking about that. At this point, Kubra could have asked the student to explain his thinking or could have invited other students to make similar connections between other length measurement units in addition to centimeter and meter. McClain, Cobb, Gravemeijer and Estes (1999) mentioned that encouraging students to explain their strategies helps to improve students' mathematical thinking. In the same way, Mason (2015) stated that teachers should closely engage with their students' ideas to support mathematical learning. That is, Kubra could have used this moment to create an active environment to support her students' discovery that a decimeter is one tenth of a meter and a centimeter is one tenth of a decimeter. Similarly, Kubra could have used her student's idea as a gateway to make a connection between decimals and length measurement units which was not part of her planned lesson but was part of her goal for the unit. Walshaw and Anthony (2008) asserted that making these connections during the lesson is difficult for most teachers, but they should be careful to look for connections between mathematical ideas. Ball (1997) stated that students' ideas are often difficult to understand. Since Kubra herself might have been challenged mathematically by the student's idea, she could not explain how the student made such a connection. To overcome this kind of challenge, teachers need to slow down and try to understand students' ideas (Jacobs \& Philipp, 2004). Since Kubra did not slow down to think about what the student was 
saying, she was unable to use the student's correct idea related to decimals to extend beyond her planned lesson for the measurement of length.

\section{Contingent Moment 2: A Student's Question-Acknowledge but Continue}

During instruction, in order to explain the relationship between a meter and a kilometer, Kubra stated that they have to multiply by 1000 or just add three zeros in order to get meters from kilometers, and they have to divide by 1000 or just "delete three zeros" to convert meters to kilometers. Afterward, the students solved some exercises requiring them to convert kilometers to meters or vice versa. Since all of these examples were very straightforward (e.g. $3 \mathrm{~km}=\ldots \ldots$.m, $14 \mathrm{~km}=\ldots \ldots . \mathrm{m}, 5000 \mathrm{~m}=\ldots \ldots \mathrm{km}$, and $21,000 \mathrm{~m}=\ldots \ldots$ $\mathrm{km}$ ), the students just deleted zeros or added zeros to find the answers. Then, Kubra asked the students to look at the textbook example (see supplementary file 3 for the example). While Kubra was explaining the difference between this particular example and the previous conversion examples, the second contingent moment resulted from a student's question which was related to the metric staircase (see supplementary file 4 for the metric staircase).

Kubra: Since the last 3 digits of the numbers are not
zeros, this example is different from the
previous m-km conversion examples. There
are not any zeros in this example, are there?
There are not 3 zeros, there is 25 . Let us
convert $2500 \mathrm{~m}$ to km by means of the metric
staircase (showing the metric staircase). Look
at here, what are we doing? We write 2500 on
the last step of the metric staircase. Then, we
will take one step upward to decameters
(equals 10 meters) and change 2500 to 250.
Then, we will take another step upward to
hectometers (equals 100 meters) and change
250 to 25 .

Students: 25.

Kubra: Now, I will take 2 one step upward; however, I will leave 5 here.

Student $_{1}$ : Why?

Students: Why?

Kubra: We have to leave one number in this step.

Students: OK.

Kubra Isn't it?

Students: Right.
Kubra tried to explain that since they cannot delete three zeros, they have to place the numbers in the metric staircase.

Similar to the previous steps, Kubra wanted to take another step upward to $\mathrm{km}$ in the metric staircase (see supplementary file 4).

However, since she accepted these steps as deleting the last digit of the number, she deleted 5 and just took 2 one step upward to $\mathrm{km}$. Therefore, she wrote the result as $2 \mathrm{~km} 500 \mathrm{~m}$.

With the student's question of "why," Kubra was confronted with an unanticipated response, and she gave a short explanation. The student was probably trying to understand conceptually why it was necessary to leave the number or take the number 
one step upward. Most likely, other students had not thought about this point until the student asked the reason for it. Kubra's explanation ("We have to leave one number in this step.") suggests that there was a procedure in her mind that she wanted to describe. Therefore, although she acknowledged the student's question, she presented a procedural explanation which was unlikely to help the students understand what was going on. She did not engage her students in thinking about why they have to leave one number in the hectometer step. This was unlikely to result in the students being able to make sense of the mathematical reason behind it. Instead, Kubra could have used her student's question as an opportunity to move students forward in reasoning about the relationship between different length measurement units.

Lehrer (2003) asserted that if teachers continue to teach the measurement concepts without unpacking the reasoning that underpins the conversion rules, students will continue to reapply the rules presented by their teachers. Improving students' reasoning is important as it engages students in doing mathematics which allows them to learn mathematics in a connected, robust, and related way (Askew, 2012). Kubra responded to her student's question procedurally, and she did not probe her students' conceptual understanding about conversion of length measurement units. When the reason for her response was questioned during the interview, Kubra herself recognized that she could not explain it effectively. Furthermore, she stated that if she had a chance to reteach this moment, she would explain that "since a kilometer is equal to 1000 meters, in order to see how many kilometers there are in 2500 meters, the obvious and easy way is to divide 2500 by 1000 , and write the result as a decimal number." Since the students had enough experience with decimals before the measurement of length instruction, Kubra could have made connections between length measurement and the use of decimals (where necessary) by building on the students' previous knowledge of decimals. Therefore, it is evident that Kubra realized this moment was a missed opportunity to explain the reason why the given number of meters has to be divided by 1000 to get kilometers. This would have been an opportunity to contribute into the flow of the measurement of length instruction and to direct students' attention to the reason behind the meter-kilometer conversion method.

\section{Contingent Moment 3: A Student's Wrong Answer-Acknowledge but Continue}

During the measurement of length instruction, Kubra used the "horizontal metric staircase" shown in Fig. 1 in addition to the metric staircase and suggested that her students use this metric staircase to convert measurement units (km-m, m-cm, cm-mm, m-mm).

Kubra stated that students can easily convert a length from a larger unit to a smaller unit by means of the metric staircase. However, she thinks that converting a length whose last digits are not zeros from a smaller unit to a larger unit by means of the metric staircase is difficult. Similarly, Kubra's students solved the examples in which they had

$\begin{array}{cccccc}\mathrm{km} \mathrm{hm} \text { dam } & \mathrm{m} & \mathrm{dm} & \mathrm{cm} & \mathrm{mm} \\ 2 & 4 & 0 & 3 & 2\end{array}$

Fig. 1 Horizontal metric staircase 
to convert the larger units $(\mathrm{km}, \mathrm{m})$ to smaller units $(\mathrm{cm}, \mathrm{mm})$ without any difficulty, as they just added zeros. When they had some difficulties, she reminded her students to use the horizontal metric staircase (In the above figure, the task is to convert $24032 \mathrm{~mm}$ to meter). Throughout the measurement of length instruction, Kubra reminded her students about the steps that needed to be followed to solve conversion examples. However, she did not provide the mathematical reasons behind these steps. That is, as mentioned before by Stephan and Clements (2003), Kubra continued to focus on the steps of the horizontal metric staircase, such as where to start to place and in which direction to continue to place the digits.

Kubra asked her students to convert $2324 \mathrm{~cm}$ to meters by means of the horizontal metric staircase. Afterward, Kubra asked one of her students to come and solve the example at the board. The student placed the digits as shown in Fig. 2, and then the following dialogue played out between Kubra and the student:

\begin{tabular}{|c|c|c|}
\hline & & Interpretation \\
\hline Kubra: & $\begin{array}{l}\text { Is this correct? What was written here? } \\
\text { (showing the } \mathrm{cm} \text { on the example) }\end{array}$ & $\begin{array}{l}\text { Since Kubra explained how to place the digits } \\
\text { into the horizontal metric staircase to find the } \\
\text { right answer, she thinks that the student will } \\
\text { remember how to do it. However, she did not. } \\
\text { So, Kubra proceeded to remind her where to } \\
\text { start writing the digits, beginning at cm. }\end{array}$ \\
\hline \multicolumn{3}{|c|}{ Student $_{2}$ : centimeter. } \\
\hline Kubra: & $\begin{array}{l}\text { What was written above your last digit? } \\
\text { (showing the mm above } 4 \text { ). } \\
\text { Let us make it correct. }\end{array}$ & \multirow[t]{2}{*}{$\begin{array}{l}\text { Kubra showed } \mathrm{mm} \text { in order to help the } \\
\text { student understand that she had started at the } \\
\text { wrong unit }(\mathrm{mm}) \text {. }\end{array}$} \\
\hline Student $_{2}$ : & $\begin{array}{l}\text { (Since she does not know where to start, she } \\
\text { writes and erases several times). }\end{array}$ & \\
\hline Kubra: & $\begin{array}{l}\text { What is our rule? We have to start by writing the } \\
\text { last digit of the number to the given length } \\
\text { measurement unit which is } \mathrm{cm} \text { in this } \\
\text { example. That is, we have to write } 4 \text { below } \\
\mathrm{cm} \text {. Then, write } 2 \text { below dm. Then, write } 3 \\
\text { below m and write } 2 \text { below dam. }\end{array}$ & $\begin{array}{l}\text { Kubra realized that the student could not } \\
\text { remember the rule. Therefore, she repeated } \\
\text { the rule step by step and the student wrote the } \\
\text { digits according to Kubra's directions. }\end{array}$ \\
\hline
\end{tabular}

As can be seen from the dialogue, the student did not know where to start. There were also other students who expressed confusion about where they should start to write the digits. Therefore, Kubra's insistence on asking students to use the horizontal metric staircase for the conversion examples did not ensure a correct answer. Teachers can use wrong answers as an effective tool to move students forward to right answers and to support students' learning (Ball, 1997). Ball (1997) also emphasized that students can feel embarrassed when they do not perform correctly. To prevent this, teachers can create a mistake-friendly classroom environment. However, Kubra's

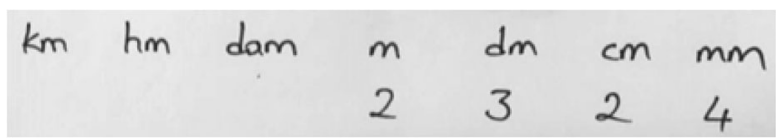

Fig. 2 A conversion example given in the horizontal metric staircase 
response was to show the student that what she had done was wrong. Although Kubra did not entirely dismiss the student's answer, she provided a list of steps needed to be applied one after another to use the horizontal metric staircase appropriately. Following these steps should ensure a correct conversion; however, the students might not understand why they apply the steps in that way. An alternative response could have been to probe the student's answer by asking questions such as, "Could you explain why you placed the numbers where you did?" or "What would be your next step?" These questions might encourage the student at the board, and might also encourage other students to assess her answer and their understanding.

Stigler and Hiebert (2009) stated that teachers with good mathematical knowledge in teaching know how to engage their students in mathematics. The moment described above was followed up during the interview with the questions "Where did you learn this horizontal metric staircase?" "Does this metric staircase work in all conversion examples" or "Why does this metric staircase work?" Kubra explained that she did not remember where she had learned it and she had not really considered why the horizontal metric staircase worked. It is clear from Kubra's explanation that she followed the steps mentioned in the above dialogue without knowing why the horizontal metric staircase worked to convert length measurement units. Therefore, Kubra's mathematical knowledge in teaching had an influence on the way in which she responded to the contingent moment. Cengiz, Kline and Grant (2011) explained that teachers need to recognize the importance and potential of contingent moments in order to respond to these moments in such a way that facilitates the flow of instruction. If Kubra had understood the reasoning that underpins the horizontal metric staircase rather than simply knowing the steps, she could have been able to understand the potential of Student,'s answer. Then, the dialogue between Kubra and Student ${ }_{2}$ could have been extended to further explain how the horizontal metric staircase can be used to make conversions and hence to contribute constructively to the flow of the measurement of length instruction.

\section{Contingent Moment 4: A Student's Question-Ignore or Dismiss}

Another contingent moment resulted from a student's question. When Kubra started to talk about the millimeter as the smallest length measurement unit, one of her students asked if there are smaller length measurement units other than a millimeter. This question could be interesting because it turns students' attention to how these length measurement units are used in their daily life. Mathematics curricula emphasize the importance of making connections between everyday life and mathematics to understand the value of mathematics in daily life. Such connections help students see the usefulness of mathematics in their daily life (Kaur, 2012). However, Kubra dismissed the student's question with "no" rather than giving more information about these units. Moreover, Kubra did not even ask why the student wanted to know about smaller length measurement units or allow her students to suggest answers. In this instance, she could have pursued the student's question by asking some questions such as "What other length measurement units can you share? When might we need a smaller length measurement unit than a millimeter? How can we measure lengths smaller than a millimeter?" Kubra could have used these discussions as an opportunity to change the flow of the instruction and extend the students' learning about length measurement units such as micrometer, nanometer, and picometer. 
Lieberman and Miller (2011) explained that teachers tend to ignore students' ideas or questions as they try to avoid distractions and continue with their intended lesson plan. In order to try to understand why Kubra responded to this contingent moment as she did, she was asked about it during the interview. She explicitly stated that although there were smaller length measurement units than a millimeter, she preferred not to mention them as it may have been difficult or confusing for the students. Of course, Kubra could have asked her students to find out if there were other units for measuring small lengths or where and for what purpose they could be used. Soliciting and then sharing their ideas could have been interesting instead of being difficult or confusing for the students.

\section{Contingent Moment 5: Availability of Materials-Extend or Make Connections}

The last contingent moment of the measurement of length instruction resulted from a task given in the textbook shown in Fig. 3, about a women's athletics $100 \mathrm{~m}$ hurdles course:

The task asked the students to find the distance between the last barrier and finish point. While the students were working on the task, Kubra circulated around the classroom to see how the students were grasping the task. Since she noticed that some of the students could not understand the task, Kubra drew a pictorial representation of it on the board (see supplementary file 5 for the representation). Using this representation, Kubra and her students discussed what is asked in the task, what information is needed to solve it, and if any unnecessary information is given in the task. This representation was helpful for the students to understand the task, thereby fostering the students' engagement and allowing some of them to discover what steps they needed to follow. However, it did not take long before Kubra noticed that there were still some students who could not understand how to solve the task. Then, Kubra noticed a rope in the cupboard and used it to model the hurdles course at the front of the class shown in Fig. 4, trying to connect the students' previous knowledge and the task. It is one thing to respond to students' questions but quite another thing to notice students' difficulties and to use available materials improvisationally. That is, Kubra had not planned to use a rope; however, the rope became available and she improvised its use. Kubra's response here was different to that discussed in the previous contingent moments, because she did not ignore the students' difficulties; instead, she tried to respond in-the-moment to the needs of the students. This moment is also important as researchers mention that since improvisation of materials provides a connection between abstract mathematics and concrete mathematics, it motivates students to learn mathematics (Ade, 2005).

\begin{tabular}{|c|c|c|c|c|c|}
\hline Category & $\begin{array}{c}\text { Number of } \\
\text { Barriers }\end{array}$ & $\begin{array}{c}\text { Height of } \\
\text { Barriers }\end{array}$ & $\begin{array}{c}\text { The distance } \\
\text { between the 1st } \\
\text { barrier and } \\
\text { starting point }\end{array}$ & $\begin{array}{c}\text { The distance } \\
\text { between the } \\
\text { barriers }\end{array}$ & $\begin{array}{c}\text { The distance } \\
\text { between the } \\
\text { last barrier and } \\
\text { finish point }\end{array}$ \\
\hline $100 \mathrm{~m}$ woman & 10 & $84 \mathrm{~cm}$ & $13 \mathrm{~m}$ & $8 \mathrm{~m} 50 \mathrm{~cm}$ & $\ldots$. \\
\hline
\end{tabular}

Fig. 3 The task from the textbook (MoNE, 4th Grade Student Lesson Textbook, 2013, p. 138) 


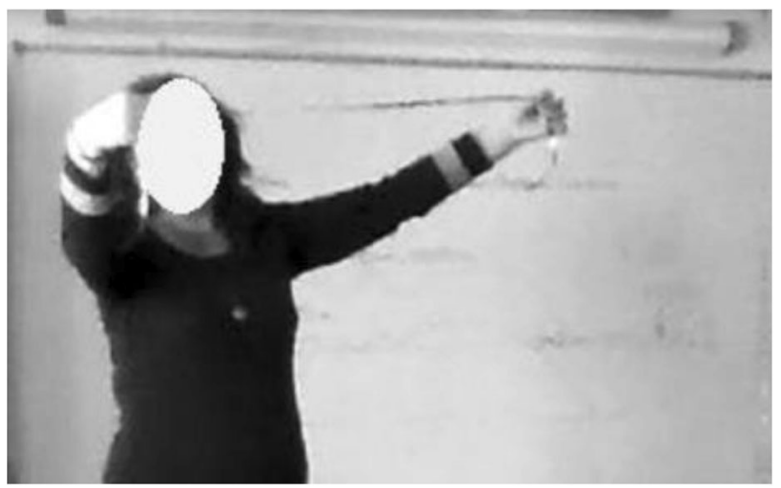

Fig. 4 Modeling the task with a rope

During this modeling, the following excerpt played out:

\begin{tabular}{|c|c|c|}
\hline & & Interpretation \\
\hline Kubra: & $\begin{array}{l}\text { Let us accept this rope as a path whose } \\
\text { length is } 100 \mathrm{~m} \text {. }\end{array}$ & $\begin{array}{l}\text { Since Kubra understood that some students had } \\
\text { trouble in solving the task, she used the rope } \\
\text { as a path to model it physically. }\end{array}$ \\
\hline
\end{tabular}

Students: OK.

Kubra: This is our starting point of the path (showing the tip of the rope) and this is our finish point (showing the other tip of the rope). OK?

Students: OK.

Kubra: What is on this path?

Before modeling the barriers, Kubra wanted her students to suggest that there could be some indicators for the given barriers in the task. Let us use knots to model the barriers.

Students: Barriers

Kubra: Yes. There are barriers. How many barriers are there?

Students: 10.

Kubra: Yes. I will tie knots to model the barriers, OK?

Students: OK.

Kubra: How many knots do I have to tie?

Students: 10.

Kubra: First knot, second knot ... (Kubra ties ten knots). Which part is asked in the task?

Students: The last part.

Kubra: What do you mean by saying the last part?

Kubra wanted to be sure that her students understood what was asked in the task, before asking her students to solve it.

Student ${ }_{1}$ : Between the last knot and the tip of the rope.

Kubra: Right. The task asks the distance here.

As can be understood from the excerpt, Kubra helped her students engage and think about the task by modeling it using a rope. The modeling of the barriers by knots on the 
rope could be more helpful than the pictorial representation for some students since they could see the barriers physically or be involved in the process of tying knots. Teachers can use different kinds of representations, including illustrations, models, and demonstrations, to enhance students' learning and to help them see the task from different perspectives (Fox, 2018). Kubra used the rope once she noticed it in the cupboard, and it can be concluded that she effectively responded to this contingent opportunity. Furthermore, while Kubra was tying the knots, she emphasized that the distances between the knots were equal. Paying attention to these distances is important as it helped the students to discover that they can use multiplication to find the distance between the first and last barriers. This way, Kubra's students had a clear idea about what was being asked in the task and what needs to be done to solve it. Furthermore, the students were able to provide explanations of how to solve it and why these procedures made sense.

When this contingent moment and her response were investigated in the interview, Kubra said that she had not thought that her students would have trouble in solving the task and had not planned to use the rope to model the task. Furthermore, she mentioned that "since the students could not understand the story part of the problem, they could not solve it. However, modelling the problem helped the students understand it." Since Kubra noticed the students' inability to understand this task, she found helpful representations of it and the students were able to engage with and solve the hurdles problem. Kurumeh (2006) asserted that these sorts of representations reduce the abstractness of mathematics. Hence, it can be concluded that being able to use two representations of the problem helped Kubra's students perform the necessary arithmetic procedures to solve the problem. Kubra's behavior is also important to help the students make connections between the topics in mathematics such as multiplication and addition and make the students be competent in using their knowledge in everyday life (NCTM, 2000).

\section{Contingent Moment 6: A Student's Idea-Pursue Student Thinking}

To begin the perimeter lesson, Kubra asked her students to suggest how to calculate a notebook's perimeter. One of her students suggested measuring each side's length and then adding up all these lengths to find the perimeter. Kubra responded by acknowledging her student's suggestion and asking him to provide more information about his thinking. While the student was explaining his thinking, he discovered that there was no need to measure the length of opposite sides as their lengths would be equal. In order to help other students understand the student's suggestion, Kubra drew the notebook by placing it on the board and measured the length of each side (see supplementary file 6 for the drawing).

While Kubra was adding up the lengths of all four sides to get the perimeter, another student suggested wrapping a tape measure around the sides of the notebook. Kubra then asked this student to explain how his suggestion was different from the other student's idea. That is, Kubra highlighted the differences in their suggestions and showed that both suggestions can be used to measure the perimeter of the notebook. As Kubra examined these students' suggestions for how they could measure the perimeter, it became a starting point to help other students to think about other possible strategies. Sharing students' ideas with the whole class provides a useful mechanism for 
broadening students' mathematical thinking (Brown \& Wragg, 1993). Students also prefer a classroom environment in which they explain their thinking and share their ideas with their classmates (Kaur, 2012). Furthermore, throughout the instruction, asking and probing students' thinking enhances students' understanding and learning of the related concepts (Kazemi \& Stipek, 2001). For example, when the students were given a worksheet that included non-rectangular and rectangular geometric shapes and asked to find the perimeter of these shapes, the students found the length of each side and added these lengths for the non-rectangular ones. That is, they did not try to use the perimeter formula for the non-rectangular geometric shapes. Asking her students to verbalize their thinking at the beginning of the perimeter instruction may be perceived as disruptions in the lesson. However, Kubra did not see these moments as disruptive to the flow of instruction, rather the dialogues extended the students' understanding of the perimeter concept.

\section{Contingent Moment 7: A Student's Question-Extend or Make Connections}

After the students discussed how to find the perimeter of a square and a rectangle and discovered ways of doing so, Kubra wanted to talk about the perimeter of other plane figures. At this point, one of her students suggested finding the perimeter of a hexagon, and Kubra accepted the students' idea and directed this question to the whole class. We now interpret the contingent moment with which we began this paper:

\begin{tabular}{|c|c|c|}
\hline & & Interpretation \\
\hline Student $_{3}:$ & $\begin{array}{l}\text { First, we measure the length } \\
\text { of one side of a hexagon. }\end{array}$ & $\begin{array}{l}\text { Since Kubra asked Student, to explain how to } \\
\text { calculate the perimeter of a hexagon, the } \\
\text { student started with finding the length } \\
\text { of a side. }\end{array}$ \\
\hline Kubra: & Yes. & \\
\hline Student $_{3}:$ & $\begin{array}{l}\text { Then, we count how many sides the plane } \\
\text { figure has and multiply this number with the } \\
\text { length that we measured. }\end{array}$ & $\begin{array}{l}\text { Here, Student }{ }_{3} \text { tried to give a general rule to find } \\
\text { the perimeter of regular plane polygons. }\end{array}$ \\
\hline Student $_{4}:$ & But, the length of the sides may not be equal. & $\begin{array}{l}\text { Student }{ }_{4} \text { knows that the lengths of each side of } \\
\text { plane figures may not be equal. }\end{array}$ \\
\hline Student $_{3}:$ & No, they have to be equal. & $\begin{array}{l}\text { Student }{ }_{3} \text { insisted that all the lengths } \\
\text { must be equal. }\end{array}$ \\
\hline Students: & Equal. & \\
\hline Kubra & $\begin{array}{l}\text { If there is a word of "-gon" at the end } \\
\text { of a plane figure, then, the sides of it } \\
\text { must be equal in length. }\end{array}$ & $\begin{array}{l}\text { Kubra seems to accept that } \\
\text { all polygons are regular. }\end{array}$ \\
\hline
\end{tabular}

Although Kubra intended to remind her students the properties of polygons to extend and make connections, Kubra's understanding of "polygon" seems to correspond to regular polygon. Despite the fact that Kubra therefore provided her students with incorrect information, since she responded with intentionality, her response type can be considered to be extending or making connections to the lesson. However, she did not respond with probing questions such as "Are the lengths of the sides of a polygon always the same?" or "Can you give an example 
of a polygon in which the lengths of the sides are different?" Therefore, Kubra did not use this opportunity to expose the limitation of Student, ${ }_{3}$ 's explanation. This was important in affecting what the students took away from the lesson. In this case, the students might "learn" that a hexagon is a six-sided shape where all the sides have equal length. And if the sides' lengths are not equal, then the six-sided shape would not be a hexagon. Teachers need to have knowledge of students' possible misconceptions to tease them out and help them develop their conceptual understanding (Ball, 1997). Similarly, Jaworski (2004) mentioned that teachers also need to know how to overcome misconceptions. However, researchers emphasized that teachers may themselves be a source of students' misconceptions if they have similar misconceptions (Yip, 1998). In order to investigate Kubra's understanding of hexagons, in the interview, some regular hexagons with six equal sides and six equal angles were drawn on paper and also some irregular hexagons, and she was asked to choose hexagons. As she did in the classroom, Kubra stated that only the regular hexagons could be accepted as hexagons. It can therefore be concluded that Kubra's misconception could be a source for Student 3 and other students who responded in the same way. Ball (1997) emphasized that if teachers' mathematical knowledge for teaching is limited, they may not appropriately respond to students' misconceptions. Therefore, it can be concluded that since Kubra's knowledge of the concept of polygons seemed to be limited, she could not generate a discussion among her students to extend the students' understanding of hexagons; instead her response reinforced the students' misconception about hexagons. To overcome such misconceptions, it is important for teachers to be aware that they may have misconceptions themselves.

\section{Conclusions and Suggestions}

The findings revealed that the contingent moments in Kubra's lessons on the measurement of length and perimeter resulted from the students' questions, ideas, and wrong answers, and from the availability of materials. This finding extends the related literature by providing a contingent moment that resulted from availability of materials (Abdulhamid, 2017; Kleve \& Solem, 2015; Rowland et al., 2015). This finding might encourage in-service teachers to use materials available to themselves in their classrooms. A contingent moment triggered by teacher insight was not observed: in fact this type of trigger is less common when compared to the other types (Rowland et al., 2015).

The responses to the contingent moments of the measurement of length and perimeter instruction fell into four types identified by Stockero and Van Zoest (2013): to ignore or to dismiss, to acknowledge but to continue, to extend or to make connections, and to pursue student thinking. Each of these response types has provided insights into how they may affect the way the lesson develops and how it proceeds. Specifically, when the teacher ignored or acknowledged students' ideas but continued the lesson without attending to and interpreting these ideas, she could not use the ideas to constructively contribute to the flow of the measurement of length and perimeter instruction. However, it does not follow that the other response types, i.e. to extend or to make connections and pursue student thinking, would necessarily contribute to the 
flow of instruction. Although the teacher intended to extend or make connections while responding, she could not contribute to the students' understanding of hexagons because of the limitations in her own mathematical content knowledge. This finding shows that teachers' mathematical knowledge in teaching might affect their responses regardless of their intention. Therefore, the findings may provide a basis for further and deeper studies about how teachers' mathematical knowledge in teaching affect their responses. In other words, making teachers aware that their own misconceptions impact the ways in which they respond to contingent moments deserves further attention. Subsequently, appropriate studies can be carried out to improve teachers' mathematical knowledge in teaching, and to help them respond appropriately to these moments. Future studies could also explore how different types of responses to contingent moments impact students' understanding.

\section{References}

Abdulhamid, L. (2017). Characterizing responsive primary mathematics teaching in the South African context. In M. Graven \& H. Venkat (Eds.), Improving primary mathematics education, teaching and learning. Research for development in resource-constrained contexts (pp. 199-216). Basingstoke, UK: Palgrave.

Ade, S. (2005). Mathematics methodology and techniques. Hillsdale, MI: Laurence Erlbaum Press.

Anthony, G., Hunter, J., \& Hunter, R. (2015). Supporting prospective teachers to notice students' mathematical thinking through rehearsal activities. Mathematics Teacher Education and Development, 17(2), 7-24.

Askew, M. (2012). Transforming primary mathematics. New York, NY: Routledge.

Ball, D. L. (1997). What do students know? Facing challenges of distance, context, and desire in trying to hear children. In B. J. Biddle, T. L. Good, \& I. F. Goodson (Eds.), International handbook of teachers and teaching (Vol. II, pp. 769-818). Dordrecht, The Netherlands: Kluwer.

Baturo, A., \& Nason, R. (1996). Student teachers' subject matter knowledge within the domain of area measurement. Educational Studies in Mathematics, 31(3), 235-268.

Bragg, P., \& Outhred, N. L. (2004). A measure of rulers - the importance of units in a measure. In M. J. Høines \& A. B. Fuglestad (Eds.), Proceedings of the 28th annual conference of the International Group for the Psychology of Mathematics Education (Vol. 2, pp. 159-166). Bergen, Norway: Program Committee.

Brookfield, S. D. (2006). The skillful teacher: On technique, trust, and responsiveness in the classroom (2nd ed.). San Francisco, CA: Wiley.

Brown, G., \& Wragg, E. C. (1993). Questioning. London, England: Routledge.

Cengiz, N., Kline, K., \& Grant, T. J. (2011). Extending students' mathematical thinking during whole-group discussions. Journal of Mathematics Teacher Education, 14(5), 355-374.

Cross, D. I. (2009). Alignment, cohesion, and change: Examining mathematics teachers' belief structures and their influence on instructional practices. Journal of Mathematics Teacher Education, 12(5), 325-346.

Davis, B. (1997). Listening for differences: An evolving conception of mathematics teaching. Journal for Research in Mathematics Education, 28(3), 355-376.

Ericsson, K., \& Simon, H. (1999). Protocol analysis: Verbal reports as data (3rd ed.). Cambridge, MA: MIT Press.

Forzani, F. (2014). Understanding "core practices" and "practice-based" teacher education: Learning from the past. Journal of Teacher Education, 65(4), 357-368.

Foster, C. (2015). Exploiting unexpected situations in the mathematics classroom. International Journal of Science and Mathematics Education, 13(5), 1065-1088.

Fox, R. D. (2018). Pre-service elementary teachers' generation of multiple representations to word problems involving proportions. In G. J. Stylianides \& K. Hino (Eds.), Research advances in the mathematical education of pre-service elementary teachers: An international perspective (pp. 55-69). Cham, Switzerland: Springer. 
Gass, S., \& Mackey, A. (2000). Stimulated recall methodology in second language research. Mahwah, NJ: Lawrence Erlbaum Associates.

Jacobs, V. R., \& Empson, S. B. (2016). Responding to children's mathematical thinking in the moment: An emerging framework of teaching moves. ZDM, 48(1-2), 185-197.

Jacobs, V. R., Lamb, L. C., \& Philipp, R. A. (2010). Professional noticing of children's mathematical thinking. Journal for Research in Mathematics Education, 41(2), 169-202.

Jacobs, V. R., \& Philipp, R. A. (2004). Mathematical thinking: Helping prospective and practicing teachers focus. Teaching Children Mathematics, 11(4), 194-201.

Jaworski, B. (2004). Insiders and outsiders in mathematics teaching development: The design and study of classroom activity. Research in Mathematics Education, 6(1), 3-22.

Kaur, B. (2012). Low attainers in primary mathematics. Singapore: World Scientific.

Kazemi, E., \& Stipek, D. (2001). Promoting conceptual thinking in four upper-elementary mathematics classrooms. The Elementary School Journal, 102(1), 59-80.

Kilundo, J. M. (2002). Evaluation of instructional materials and their use in power mechanics and drawing and design in Kenyan secondary schools. M.Phil Thesis Moi University.

Kleve, B., \& Solem, I. H. (2015). A contingent opportunity taken investigating in-between fractions. In K. Krainer \& N. Vondrová (Eds.), Proceedings of the Ninth Congress of the European Society for Research in Mathematics Education (pp. 3051-3058). Prague, Czech Republic: Charles University in Prague, Faculty of Education and ERME.

Kurumeh, M. S. (2006). Effect of ethnomathematics approach on students' achievement in geometry and menstruation. Journal of Mathematical Association of Nigeria, 31(1), 35-44.

Lampert, M. (2001). Teaching problems and the problems of teaching. New Haven, CT: Yale University Press.

Lehrer, R. (2003). Developing understanding of measurement. In J. Kilpatrick, W. G. Martin, \& D. Schifter (Eds.), A research companion to principles and standards for school mathematics (pp. 179-192). Reston, VA: National Council of Teachers of Mathematics.

Lieberman, A., \& Miller, L. (2011). Learning communities: The starting point for professional learning is in schools and classrooms. Journal of Staff Development, 32(4), 16-20.

Mackey, A. (2012). Input, interaction, and corrective feedback in L2 learning. Oxford, England: Oxford University Press.

Mason, J. (2015). Responding in-the-moment: Learning to prepare for the unexpected. Research in Mathematics Education, 17(2), 110-127.

McClain, K., Cobb, P., Gravemeijer, K., \& Estes, B. (1999). Developing mathematical reasoning within the context of measurement. In L. Steffe (Ed.), Developing mathematical reasoning in grades K-12. Reston, VA: NCTM.

Ministry of National Education. (2013). Fourth grade mathematics student's book (5th ed.). Ankara, Turkey: Devlet Kitapları Mudurlugu.

Ministry of National Education. (2015). Primary schools mathematics program for 1, 2, 3, and 4 grades. Ankara, Turkey: Devlet Kitapları Mudurlugu.

National Council of Teachers of Mathematics. (2000). Principles and standards for school mathematics. Reston, VA: Author.

Patton, M. Q. (2002). Qualitative research \& evaluation methods (3rd ed.). Thousand Oaks, CA: Sage.

Sawyer, R. K. (2004). Creative teaching: Collaborative discussion as disciplined improvisation. Educational Researcher, 33(2), 12-20.

Schoenfeld, A. H. (1998). Toward a theory of teaching-in-context. Issues in Education, 4(1), 1-94.

Sherman, H., \& Randolph, T. (2004). Area and perimeter: "Which is which and how do we know?". Research for Educational Reform, 9(3), 25-36.

Silverman, D. (1993). Interpreting qualitative data. Methods for analysing talk, text and interaction. Londres, England: Sage.

Smith, L. A., Sterling, D. R., \& Moyer-Packenham, P. S. (2006). Activities that really measure up. Science and Children, 44(2), 30-33.

Stake, R. (1995). The art of case study research. Thousand Oaks, CA: Sage.

Stephan, M., \& Clements, D. H. (2003). Linear and area measurement in prekindergarten to grade 2. In D. H. Clements \& G. Bright (Eds.), Learning and teaching measurement: 2003 yearbook (pp. 3-16). Reston, VA: National Council of Teachers of Mathematics.

Stigler, J. W., \& Hiebert, J. (2009). The teaching gap: Best ideas from the world's teachers for improving education in the classroom. New York, NY: The Free Press, A Division of Simon \& Schuster Inc.

Stockero, S. L., \& Van Zoest, L. R. (2013). Characterizing pivotal teaching moments in beginning mathematics teachers' practice. Journal of Mathematics Teacher Education, 16(2), 125-147. 
Rowland, T., Zazkis, R. (2013). Contingency in the Mathematics Classroom: Opportunities Taken and Opportunities Missed. Canadian Journal of Science, Mathematics and Technology Education 13 (2): 137-153

Rowland, T., Thwaites, A., Jared, L. (2015). Triggers of contingency in mathematics teaching. Research in Mathematics Education 17 (2):74-91

Towers, J., \& Davis, B. (2002). Structuring occasions. Educational Studies in Mathematics, 49(3), 313-340.

Walshaw, M., \& Anthony, G. (2008). The teacher's role in classroom discourse: A review of recent research into mathematics classrooms. Review of Educational Research, 78(3), 516-551.

Yin, R. K. (2002). Case study research: Design and methods. Thousand Oaks, CA: SAGE Publications.

Yip, D. Y. (1998). Identification of misconceptions in novice biology teachers and remedial strategies for improving biology learning. International Journal of Science Education, 20(4), 461-477.

\section{Affiliations}

\section{Sumeyra Dogan Coskun ${ }^{1} \cdot$ Mine Isiksal Bostan ${ }^{2} \cdot$ Tim Rowland $^{3}$}

1 Department of Elementary and Early Childhood Education, Faculty of Education, Eskisehir Osmangazi University, 26040 Eskisehir, Turkey

2 Department of Mathematics and Science Education, Faculty of Education, Middle East Technical University, 06800 Ankara, Turkey

3 School of Education and Lifelong Learning, University of East Anglia, Norwich, UK 